\title{
N-3 HUFA'ca zenginleştirilmiş Artemia ile beslenen Yeşil kaplan karidesi (Penaeus semisulcatus) larvalarının büyüme performansı
}

\author{
Hatice Asuman Y1lmaz ${ }^{1^{*}}$ \\ 1* Çukurova Üniversitesi, Su Ürünleri Fakültesi, Yetiştiricilik Anabilim Dal1, Adana, Türkiye, (ORCID: 0000-0001-5627-034X), ayilmaz@cu.edu.tr
}

(İlk Geliş Tarihi 5 Ağustos 2020 ve Kabul Tarihi 8 Ekim 2020)

(DOI: $10.31590 /$ ejosat.776363)

\begin{abstract}
ATIF/REFERENCE: Yılmaz, H.A. (2020). N-3 HUFA'ca zenginleştirilmiş Artemia ile beslenen Yeşil kaplan karidesi (Penaeus semisulcatus) larvalarının büyüme performansı. Avrupa Bilim ve Teknoloji Dergisi, (20), 30-34.

$\ddot{O} z$

Artemia zenginleştirmesinin karides larvaları üzerindeki etkileri konusunda önemli miktarda çalışmalar yapılmıştır. Penaeid karideslerin, yüksek oranda doymamış yağ asitlerinin (n-3 HUFA) sentezlemede sınırlı bir yeteneğine sahip olduğu iyi bilinmektedir. $\mathrm{Bu}$ çalışma, deneylerde yeşil kaplan karidesi (Penaeus semisulcatus) larva kültürü sırasında yüksek oranda n-3 HUFA ile zenginleştirilen Artemianın büyüme ve hayatta kalma üzerine etkilerini araştırmak için yapılmıştır. Mysis I'den postlarvalara (PL9) on bir güne kadar $P$. semiculcatus larvalarının zenginleştirilmemiş Artemia (WE) ve yüksek seviyelerde n-3 HUFA içeren bir emülsiyon (SELC) ile zenginleştirilmiş Artemialar (Artemia nauplii) ile beslenerek büyüme performansları ve hayatta kalma oranları araştırılmıştır. Deneme sonunda, zenginleştirilmiş Artemia'da daha yüksek n-3 HUFA, özellikle 20:5n-3 ve 22:6n-3 seviyeleri bulunmuştur. M1'den PL1'e veya PL9'a büyütülen larvalar, SELC tedavilerinde daha yüksek yaşama oranı (PL1'de \%93.20 veya PL7'de \%79.13) göstermiştir. PL1'deki toplam uzunluk (TL) (sırasıyla 5.33-5.34 mm TL) gruplar arasında anlamlı farklılık göstermemiştir. Ancak, son toplam PL9 uzunluğu SELC'de (9.25 mm / gün TL) WE'den (8.97 mm / gün TL) önemli ölçüde daha yüksek bulunmuştur. Larva yetiştiriciliği sırasında n-3 HUFA'nın takviyesi, postlarvalarda $P$. semisulcatus'un yaşama toleransını arttırmış, 12 gün sonra büyüme performansını olumlu yönde etkilemiştir. N-3 HUFA ile zenginleştirilmiş Artemia, büyüme oranını olumlu yönde etkileyebilir ve $P$. semisulcatus'un erken aşamalarının toplam uzunluğunu ve hayatta kalmasını etkili bir şekilde artırabilir. Ek olarak, sonuçlar karma yemlere geçmeden önce n-3 HUFA ile zenginleştirilmiş Artemia kullanmanın büyüme performansının yanı sıra çevresel etkiler üzerinde de etkili olabileceğini göstermiştir. Bu durum, entansif kuluçkahaneler için açık bir potansiyel uygulama olarak kabul edilmektedir. Larvaların geçiş aşamasında çok karşılaşılan hayatta kalma problemleri için kullanılması önerilmektedir.
\end{abstract}

Anahtar Kelimeler: Penaeus semisulcatus, zenginleştirme, büyüme performansı, hayatta kalma

\section{The Effect of Enriched Artemia of N-3 HUFA on the growth performance of Green tiger shrimp (Penaeus semisulcatus) larvae}

\begin{abstract}
A significant amount of work has been done on the effects of Artemia enrichment on shrimp larvae. It is well known that penaeid shrimps have a limited ability to synthesize highly unsaturated fatty acids (n-3 HUFA). This study was carried out to investigate the effects of enrichment artemia with n-3 HUFA on growth and survival during the larval culturing of Penaeus semisulcatus in experiments. P. semisulcatus larvea from Mysis I to eleven days postlarvae (PL9) were fed without Artemia-enriched (Artemia nauplii) (WE) and an emulsion containing high levels of n-3 HUFA (SELC). In the end of the experiment, higher levels of n-3 HUFA, especially 20:5n-3 and 22:6n-3, were found in the enriched Artemia. The larvae grown from M1 to PL1 or to PL9 displayed higher survival (93.20\% at PL1 or 79.13\% at PL9) in SELC treatments. The total length (TL) at PL1 (5.33-5.34 mm TL, respectively) did not significantly differences between groups. However, final total length of PL9 was significantly higher in SELC (9.25 mm/day TL) than in WE $(8.97 \mathrm{~mm} /$ day TL). Supplementation of n-3 HUFA during larviculture increases the survival tolerance of $P$. semisulcatus in postlarvae, positively affects growth performance after 12 days. N-3 HUFA enriched Artemia can positively affect growth rate and effectively improve the total length and survival of the early stages of $P$. semisulcatus. In addition, the results showed better effects on growth performance and environmental effects using Artemia enriched before switching to this type of mixed feed. This is considered to be an obvious potential application for intensive hatcheries. This is considered to be a clear potential application for intensive hatcheries. It is recommended to use the larvae for survival problems that are frequently encountered during the transition phase.
\end{abstract}

Keywords: Peneseaus semisulcatus, enrichment, growth performance, survivial

*Sorumlu Yazar: ayilmaz@cu.edu.tr 


\section{Giriş}

Dünya su ürünleri üretiminde önemli bir yer tutan karides üretiminin 2015 yılı itibariyle yaklaşık 4 milyon tonun üzerine çıktığı ve üretimin ekonomik değerinin yaklaşık 14-15 milyar ABD dolarına ulaştığı bildirilmektedir (FAO, 2016). Ancak bu ekonomik değerin yem, imalatı, işleme, depolama, ticari faaliyetler ve pazarlama gibi giderlerle çok daha yüksek olduğu tahmin edilmektedir. Bilindiği gibi ülkemiz su ürünleri yetiştiricilik sektörü alabalık, çipura ve levrek üretimi ile sınırlı kalmıştır. Ancak son yıllarda ülkemizde de su ürünleri üretiminde tür çeşitliliğini arttırmaya yönelik farkındalık artmış ve alternatif türlerin üretime katılması gerekliliği gündeme gelmiştir.

Karidesler en yoğun şekilde yetiştirilen türler arasında ve ticari su ürünleri yetiştiriciliği sistemlerinde yüksek talep gören türler arasındadır; ancak, başarılı karides larva kültürü su ürünleri yetiştiriciliği kullanılan Artemia kalitesinden etkilenmektedir. Karideslerin yaşam döngüsünde larva ve postlarval aşamalar, bu aşamaların sonraki gelişim aşamalarını doğrudan etkilemesi nedeniyle yaşam döngüsünün önemli bir bölümünü oluşturmaktadır. Karidesler soğukkanlı organizmalardır ve bu nedenle membran akışkanlığını korumak için dokularında daha fazla miktarda çoklu doymamış yağ asitleri (PUFA) gerekir (Bell ve ark. 1986). Ac1 su ve deniz kabukluları ve yumuşakçalar için gerekli olan en önemli esansiyel yağ asitleri, yüksek oranda doymamış yă asitleri (HUFA), özellikle eikosa-pentaenoik asit (20: 5 n-3; EPA) ve dokosaheksaenoik asittir (22: 6 n-3; DHA). Penaeid karideslerin n-3 HUFA de novo sentezini yapma konusunda sinırlı bir yeteneğe sahip oldukları iyi bilinmektedir. Bu ilk olarak Marsupenaeus japonicus (Kanazawa ve ark., 1979a), Penaeus monodon ve Fenneropenaeus merguiensis (Kanazawa ve ark., 1979b) yapılan çalışmalarla gösterilmiştir. HUFA, özellikle EPA ve DHA, normal hücre fonksiyonunun korunmasında hayati öneme sahiptir; EPA ve DHA, hücre zarı oluşumu, osmoregülasyon, prostaglandin sentezi için gerekli olan temel bileşiklerdir ve ayrıca bağışıklık sisteminde aktive edici bir rol oynadıkları görülmektedir (Lèger ve Sorgeloos, 1992). Bu nedenle, penaeid karideslerin beslenmesinde kullanılan yemlerde bu temel besin maddeleri yeterli miktarda içermelidir.

Penaeus semisulcatus, Doğu Akdeniz kıyılarında dağılım gösteren bir Hint-Pasifik türüdür ve dünyanın bu bölgesindeki en önemli ticari türlerden biridir. P. semisulcatus için optimal tuzluluk 30-35 ppt'dir (Kumlu, 1999). Doğu Akdeniz'de yumurtalı dişiler genellikle yılın daha serin aylarında yakalandığından dolayı, bu türün alt tropikal koşullarda karşılaşılan serin sulara adapte olabileceği düşünülmektedir. Sektörde geliştirilmiş olan mikropartikül, mikrokapsül gibi çeşitli yapay yem tiplerine karşın (Leger ve ark, 1986; Jones ve ark, 1993), halen larva yetiştiriciliğinde, geleneksel olarak canlı rotifer ve Artemia kullanımı çok yaygındır. Penaeid karides postlarvalarının üretimi, ticari kuluçkahanelerde kullanılan besin Artemia'ya dayanmaktadır (Sorgeloos ve ark., 1998; Wouters ve ark., 2009; Cobo ve ark., 2015). Artemia yüksek protein ( $\%$ 52) ve yă̆ ( $\sim \% 14)$ içeriği nedeniyle karides larva kültürlerinde kullanılan en yaygın kullanılan canlı yemlerden biridir. Kuluçkahane yönetimi açısından Artemia'nın kullanımı çeşitli avantajlar sunsa da en önemlisi depolama ve kullanım kolaylığıdır (Lèger ve Sorgeloos, 1992). Yeni açılmış Artemia nauplii'deki n-3 HUFA seviyeleri düşük veya büyük ölçüde değişkenlik göstermektedir (Lavens ve Sorgeloos, 1996; Figueiredo ve ark., 2009). Bu nedenle EPA içeriğindeki değişkenliğin yanı sıra karides larva kültüründe kullanılan geleneksel canlı yemlerde önemli seviyelerde DHA, n-3 HUFA ile zenginleştirilmiş ürünlerin (örn. Mikrokapsüller, emülsiyonlar, mikro-partikül) ticari gelişimi üzerine araştırmaları teşvik etmiştir. Artemia seçici olmayan bir filtre beslenme özelliği olduğundan, n-3 HUFA seviyelerinin arttırılmasında, Artemia'ya n-3 HUFA bakımından zengin bileşiklerin verilmesi yoluyla besin değerlerini arttıran zenginleştirme teknikleri uygulanmaktadır (Sorgeloos ve ark., 1998; Wouters ve ark., 2009).Önceki çalışmalar, n-3 HUFA bakımından zengin yemlerle beslemenin çok sayıda kabuklu türünde hayatta kalma ve büyüme üzerine olumlu etkilerini bildirmişlerdir (Tackaert ve ark., 1989; Rees ve ark., 1994; Cavalli ve ark., 2000; Chim ve ark., 2001; Martins ve ark., 2006; Immanuel ve ark., 2007; Sui ve ark., 2007; Jinbo ve ark., 2013; Mutti ve ark., 2017).

SELCO zenginleştiricisi deniz balıkları ve krustaselerinin larva yetiştiriciliğinde başarı için, besleme protokollerinde kullanılması gerekli olan ve fakat HUFA'larca oldukça fakir olduğu bilinen canlı larva besinlerinden rotifer ve Artemia'nın n3 esansiyel yağ asitlerini (özellikle DHA ve EPA gibi) arttırmak amacıyla denizel kuluçkahanelerde yaygın olarak kullanılan bir zenginleştirici emülsiyondur (Sorgeloos ve ark, 2001). Bu nedenle, bu çalışma Artemia'teki n-3 HUFA'nın, mysis 1 aşaması (M1) ile postlarva 9 (PL9) dönemleri arasındaki yeşil kaplan karidesinde büyüme ve hayatta kalma oranlarını belirlemek için kurgulanmıştır. Ayrıca, n-3 HUFA'nın besinsel ve fonksiyonel önemini anlamak için, bu çalışma, zenginleştirilmemiş Artemia $s p$. ile beslenen yeşil kaplan karides larvalarının büyüme performansları karşılaştırılmıştır.

\section{Materyal ve Metot}

Denemede kullanılan Yeşil kaplan karides (P. semisulcatus) anaçları Adana ili Yumurtalık ilçesinde faaliyet gösteren balıkçılar tarafindan uzatma ağı ile 3-4. aşamada olan dişi ve 25-30 g ağırlığındaki erkek anaçlar doğadan yakalanarak temin edilmiştir.

Gonad gelişimlerini teşvik etmek için karidesler su tuzluluğu 35-40 ppt, su sicaklığ $28-30^{\circ} \mathrm{C}$, oksijeni $6-7 \mathrm{mgL}^{-1}$, pH'sı 7.5 -8.0 olan ve en az \%150 su değişimi yapılan $2 \mathrm{~m}$ çapındaki anaç tanklarına alınmışlardır. $\mathrm{Bu}$ süre içerisinde, anaçların beslenmesinde taze kalamar ve yengeç kullanılmıştır. Anaçların yumurtalık gelişimleri gözlemlenerek 4. aşamada olan anaçlar 30 ppt tuzlulukta ve $28^{\circ} \mathrm{C}$ sicaklıkta olan yumurtlama tankına alınarak yumurtlatılmaları sağlanmıştır. Yumurtalama olduktan sonra anaçlar yumurtlama tankından alınarak yumurtlamanın yoğunluğuna ve kalitesine bakılarak açılma süreleri beklenmiştir. Larvalar açıldıktan 24 saat sonrasında Kumlu, (1999) tarafından tarif edildiği gibi statik bir su kuluçka sisteminde yetiştirilmiştir. Larvalar, kültür boyunca Tetraselmis suecica (30 hücre $\mu^{-1}$ ) Phaeodactylum tricornutum (40 hücre $\mu \mathrm{l}^{-}$ $\left.{ }^{1}\right)$ ve Isochrysis galbana (30 hücre $\left.\mu^{-1}\right)$ içeren mikroalg karışımı ile beslenmişlerdir. $\mathrm{Bu}$ mikroalg türleri, Walne kültür ortamı kullanılarak kesikli kültür sisteminde üretilmiştir. Mikroalg kültüründeki, günlük hücre sayısı ve larva tanklarındaki mikroalg hücrelerinin sayısını tahmin etmek için hemositometre kullanılmıştır. Tuzluluk $34 \pm 1.0 \mathrm{ppt}$, sıcaklık $28.5 \pm 0.8^{\circ} \mathrm{C}, \mathrm{pH}$ $7.4 \pm 0.5$, çözünmüş oksijen $6.8-7.9 \mathrm{mgL}^{-1}$ ve toplam amonyak 
konsantrasyonu $<0.4 \mathrm{mgL}^{-1}$ tutularak 12 saatlik aydınlık ve 12 saatlik karanlık bir fotoperiyot uygulanmıştır.

Deneme başlangıcı larvaların mysis aşamasına geldiğinde her 2 L balon jojeye 250 adet olacak şekilde larvalar stoklanmıştır. Stoklama işlemi yapılırken her tekerrüre koyulan larvaların boyutlarına dikkat edilerek yerleştirilmiştir. Başlangıç uzunluğunu temsil etmesi amaciyla toplamda 100 adet bireyin total boy uzunluğu alınmıştır. Deneme sırasında larvalar günde iki kez (saat: 08.30 ve 20.30) ortalama 5 nauplii $\mathrm{mL}^{-1}$ artemia ile besleme yapılmıştır. Deney sisteminde her gün $\% 100$ su değişimi yapılarak ve her bir balon jojedeki tüm larvaların (PL) sayımı gerçekleştirilmiştir. Ayrıca deneme boyunca her gün 30 adet örnek alınarak mikroskop altında PL'lerin toplam uzunlukları ölçülmüştür. Kanazawa ve ark. (1985)'nın yöntemi kullanılarak büyüme indeksi çıkartılmıştır.

Deneme grupları aşağıdaki şekilde dizayn edilmiştir.

1.Grup: Zenginleştirilme yapılmamış Artemia ile beslenen larvalar (WE)

2.Grup: n-3HUFA'ca zenginleştirilmiş Artemia ile beslenen larvalar (SELC)

Kontrol grubu (WE) için larvalar yeni açılmış Artemia nauplii ile beslenirken, zenginleştirilmiş grupta (SELC) larvalar $400 \mathrm{mg}$ g1 n-3 içeren ticari bir emülsiyon (Super SELCO, INVE Aquaculture, ABD) ile zenginleştirilmiş Artemia nauplii ile beslenmişlerdir.

Yağ asidi analizleri için eksrakte edilmiş lipit kullanılarak, yağ asidi metil esterleri (FAME) Metcalfe ve Schmitz'e (1961) göre hazırlanmış ve bazı modifikasyonlarla daha önce Czesny ve Dabrowski, 1998'te tarif edildiği gibi analiz edilmiştir. Yağ asidi profillerinin belirlenmesi için GC kapiler kolon (100 m x 0.25 mm x $0.2 \mathrm{~m}$ film kalınlığı), taşıyıcı gaz olarak $2 \mathrm{ml} / \mathrm{dk}$ akış hızında hidrojen gazı ve dedektör olarak da FID dedektörü kullanılmıştır. Örnekler GC'ye enjeksiyon miktarı $1 \mu$ l olarak uygulanmıştır. Örneklerin GC analizindeki fırın sıcaklık programı; $190^{\circ} \mathrm{C}$ 'de $1 \mathrm{dk}$ bekleme, $30^{\circ} \mathrm{C} / \mathrm{dk}$ 'lik artışla $220^{\circ} \mathrm{C}$ 'ye çıkış ve bu sıcaklıkta $5 \mathrm{dk}$ bekleme şeklinde gerçekleştirilmiştir. Her bir yağ asidi çıkış zamanı (RT, tekrarlama zamanı)'ları yağ asitleri karışım standartlarının (Supelco 37 component FAME mix, Cat No: 47885-U) RT'leri ile mukayese edilmiş ve yağ asitleri tanımlanan piklerin konsantrasyonları \% olarak hesaplanmıştır.

Veriler, üç tekerrürlü olacak şekilde ortalama ve standart hata olarak hesaplanmıştır. Elde edilen veriler SPSS 17.0 istatistik paket programı kullanılarak varyans analizi (ANOVA) ile değerlendirilmiştir. İstatistiksel farklılıklar $\mathrm{p}<0.05$ önem seviyesinde Duncan testi kullanılarak belirlenmiştir.

\section{Araştırma Sonuçları ve Tartışma}

\subsection{Artemiaların Yă̆ Asidi Kompozisyonları}

Zenginleştirme işlemi Artemiaların yağ asidi bileşimini etkilemiştir (Tablo 1). 24 saat zenginleştirme sonrasında n-3 HUFA'ca zenginleştirilen Artemiaların (SELC) ve zenginleştirilmeyen artemiaların (WE) toplam doymuş yağ asitleri (SFA) arasında fark bulunmamıştır $(\mathrm{P}>0.05)$. Palmitik asit (C16:0) yağ asidi en yüksek oranda SELC grubunda \%10.43 ve WE grubunda \%10.06 bulunmuştur. MUFA içeriği açısından istatistiksel farklıklık gözlemlenirken bu değer WE grubunda \%34.17 iken SELC grubunda \%30.84 bulunmuştur $(\mathrm{P}<0.05)$.
Linoleik asit (C18:2n-6) oranınında fark bulunmazken arişidonik asit (20:4n-6) açısından WE (\%0.92) grubu SELC (\%0.75) grubuna oranla daha yüksek bulunmuş ve istatistiksel farklılık çıkmıştır $(\mathrm{P}<0.05)$. Aynı şekilde n-6 PUFA'nın zenginleştirilmiş Artemia'da miktarı daha düşükken (\%7.70) zenginleştirilmemiş artemialarda daha yüksek bulunmuştur $(\% 8.90)(\mathrm{P}<0.05)$.

Tablo 1. 24 saat süreyle SELCO ile zenginleştirme işlemi yapılan ve zenginleştirme yapılmayan Artemiaların yağ asidi (\%) komposzisyonları.

\begin{tabular}{|c|c|c|}
\hline \multirow[t]{2}{*}{ Yağ Asitleri } & \multicolumn{2}{|c|}{ Artemia (24 saat) } \\
\hline & WE & SELC \\
\hline $16: 0$ & $10.06 \pm 0.01$ & $10.43 \pm 0.01$ \\
\hline $17: 0$ & $0.67 \pm 0.09$ & $0.65 \pm 0.04$ \\
\hline 18:0 & $8.53 \pm 0.13^{\mathrm{a}}$ & $7.32 \pm 0.04^{\mathrm{b}}$ \\
\hline SFA $^{1}$ & $20.02 \pm 0.81$ & $20.45 \pm 0.50$ \\
\hline $14: 1$ & $0.88 \pm 0.06$ & $0.80 \pm 0.01$ \\
\hline $16: 1 n-7$ & $1.49 \pm 0.08$ & $1.44 \pm 0.10$ \\
\hline $18: 1 n-7$ & $9.35 \pm 0.70^{\mathrm{a}}$ & $7.73 \pm 0.25^{\mathrm{b}}$ \\
\hline $18: 1 n-9$ & $21.83 \pm 0.18^{\mathrm{a}}$ & $19.32 \pm 0.02^{b}$ \\
\hline MUFA $^{2}$ & $34.17 \pm 0.40^{\mathrm{a}}$ & $30.84 \pm 1.01^{\mathrm{b}}$ \\
\hline $18: 2 n-6$ & $6.00 \pm 0.06$ & $6.17 \pm 0.29$ \\
\hline $18: 3 n-6$ & $0.66 \pm 0.01^{\mathrm{a}}$ & $0.49 \pm 0.03^{\mathrm{b}}$ \\
\hline $20: 4 n-6$ & $0.92 \pm 0.02^{\mathrm{a}}$ & $0.75 \pm 0.05^{\mathrm{b}}$ \\
\hline n-6 PUFA ${ }^{3}$ & $8.90 \pm 0.01^{\mathrm{a}}$ & $7.70 \pm 0.39^{b}$ \\
\hline $18: 3 n-3$ & $24.16 \pm 0.04$ & $24.04 \pm 0.06$ \\
\hline $20: 3 n-3$ & $1.02 \pm 0.01$ & $1.09 \pm 0.00$ \\
\hline $20: 5 n-3$ & $2.01 \pm 0.36^{\mathrm{b}}$ & $5.34 \pm 0.36^{\mathrm{a}}$ \\
\hline $22: 6 n-3$ & $1.20 \pm 0.12^{\mathrm{b}}$ & $4.16 \pm 0.09^{\mathrm{a}}$ \\
\hline n-3 PUFA ${ }^{4}$ & $31.21 \pm 0.87^{b}$ & $35.80 \pm 0.31^{\mathrm{a}}$ \\
\hline$\sum$ PUFA & $41.77 \pm 0.82$ & $43.54 \pm 0.08$ \\
\hline $\mathrm{EPA}+\mathrm{DHA}$ & $3.21 \pm 0.99^{b}$ & $9.40 \pm 0.34^{\mathrm{a}}$ \\
\hline
\end{tabular}

${ }^{1}$ SFA: 12:0, 14:0, 15:0, 16:0, 17:0, 18:0, 20:0, 22:0, 24:0.

${ }^{2}$ MUFA: $16: 1 \mathrm{n}-7,18: 1 \mathrm{n}-7,18: 1 \mathrm{n}-9,20: 1 \mathrm{n}-9,22: 1 \mathrm{n}-11,22: 1 \mathrm{n}-9$, 24:1n-9.

${ }^{3} \mathrm{n}-6$ PUFA: $18: 2 \mathrm{n}-6,18: 3 \mathrm{n}-6,20: 2 \mathrm{n}-6,20: 3 \mathrm{n}-6,20: 4 \mathrm{n}-6$.

${ }^{4} n-3$ PUFA: $18: 3 n-3,18: 4 n-3,20: 4 n-3,20: 5 n-3,22: 5 n-3,22: 6 n-3$.

Linoleik asit (18:3n-3) içeriği açısndan SELC ve WE grupları arasında istatistiki açıdan farklılık bulunmazken bu değer yaklaşık \%24 civarında tespit edilmiştir. EPA ve DHA miktarları incelendiğinde SELC ve WE grupları arasında istatistiki açıdan farklı çıkmıştır. EPA değeri SELC grubunda \%5.34 ve DHA değeri \%4.16 bulunurken, WE grubunda sirasıly \%2.01 ve $\% 1.20$ olarak tespit edilmiştir $(\mathrm{P}<0.05)$. Toplam $\mathrm{n}-3$ çoklu doymamış yağ asitleri (n-3 PUFA), beklenildiği gibi zenginleştirilen Artemialarda daha yüksek oranda bulunurken (SELC; \%35.80), zenginleştirme yapılmayan Artemialarda düşük oranda tespit edilmiştir (WE; \%31.20). Toplam PUFA açısından gruplar arasında farklılık bulunmazken $(\mathrm{P}>0.05)$, zenginleştirilen Artemiaların EPA+DHA miktarı zenginleşmemiş Artemiaların 2.93 kat daha yüksek bulunmuştur. SELC grubunda bu oran \%9.40 olarak tespit edilmiştir.

Acı su ve deniz kabukluları ile yumuşakçalar için gerekli olan en önemli esansiyel yağ asitleri, yüksek oranda doymamış yağ asitleri (HUFA), özellikle AA, EPA ve DHA'dır. EPA içeriğindeki değişkenliğin yanı sıra karides larva kültüründe 
kullanılan geleneksel canlı yemlerde önemli seviyelerde DHA bulunmaması, n-3 HUFA ile zenginleştirilmiş ürünlerin (örn. mikrokapsüller, emülsiyonlar, mikro-partikül) ticari gelişimi üzerine araştırmaları teşvik etmiştir (Dianna ve ark., 2017). Takeuchi ve ark (1999) ile Suprayudi ve ark (2004) bir canlı yem kaynağı olarak Artemia'nın düşük seviyede EPA ve yok denecek kadar düşük seviyede DHA içerdiğini ve bundan dolayı da larva beslemede kullanılmadan önce mutlaka zenginleștirilmeleri gerektiğini bildirmişlerdir. Velu ve Munuswamy (2004) peri karideslerinde (Streptocephalus dichtomus) farkl1 zenginleştiricilerle (ALGAMAC 2000 ve DHA-DELCO) farklı sürelerde HUFA'ca zenginleştirmiş ve bu karideslerdeki yă asitleri profillerini incelediklerinde peri karidesinin linoleik, linolenik, EPA ve DHA seviyelerinin belirgin bir şekilde yükseltilebildiğini ve böylece bu canlının anaç karides beslemede canlı yem kaynağı olarak kullanılabileceğini bildirmiştir. Ayrıca zenginleştirme işleminde sonra Artemiaların yağ asidi kompozisyonlarındaki farklılığın zenginleştirme miktarı ve süresine bağlı olduğu görülmüştür.

\subsection{Büyüme Parametreleri}

Deneme sonunda larvaların hayatta kalma oranları \%73.0 ile \%79.1 arasında değişim göstermiş olup gruplar arasında istatistiki farklılık bulunmuştur $(\mathrm{P}<0.005)$. Deneme mysis $1(\mathrm{M} 1)$ aşamasında başlamış her gün ölçümler yapılarak günlük olarak kaydedilen veriler doğrultusunda, postlarva 1 (PL1) aşamasına geldiğinde SELC ile beslenen larvaların yaşama oranları WE ile beslenen larvalara göre daha iyi oranda olduğu saptanmıştır (Tablo 2). PL1 aşamasında en iyi hayatta kalma oranı SELC grubu bireylerinde \%93.20 olarak saptanmıştır.

Grupların büyüme oranları karşılaştırıldığında M1-PL1 ve M1-PL9 dönemleri arasında SELC bireyleri istatistiki açıdan daha iyi performans göstermişlerdir. Total boy açısından PL1 aşamasına kadar iki grubun total boyları yakın saptanırken PL9 aşamasına gelindiğinde SELC grubu bireylerin total boyları daha uzun ölçülmüştür. Bu dönemde gruplar arasında istatistiki açıdan farklılık bulunmuşltur (Tablo 2).
Artemia'nın zenginleştirilmesi, tüm dünyada deniz balıkları ve kabuklu kuluçkahanelerinde, temel yă as asitleri ile Artemia'nın besin değerini artırmak için yaygın olarak uygulanmaktadır (Van Stappen 1996; Agh ve Sorgeloos 2005). Artemia, ilkel beslenme özellikleri nedeniyle biyokimyasal bileşimi etkilemenin en uygun yolundan biridir. $\mathrm{Bu}$ nedenle, özellikle n-3 HUFA'ları Artemiaları zenginleştirmek kullanılan yöntemlerden biridir. Elde ettiğimiz bulgular, n-3 HUFA ile Artemia'nın zenginleştirilmesinin, diğer kabuklularda olduğu gibi $P$. semisulcatus'un larvalarının hayatta kalması ve büyümesi için etkili olduğunu açıkça göstermiştir.

Gerekli besinleri sağlayan ve hayatta kalmayı artıran yem bileşenlerinin kullanılması larva kalitesini artırmak için önemlidir. Karidesler soğukkanlı organizmalardır ve bu nedenle membran akışkanlığını korumak için dokularında daha fazla miktarda çoklu doymamış yağ asidi (PUFA) gerekir (Bell ve ark. 1986). Kabukluların yemlerinde n-3 HUFA sağlanmasının olumlu bir etkisi, genellikle daha yüksek stres toleransı ile sonuçlanmasıdır (Tackaert ve ark., 1989; Dhert ve ark., 1992; Rees ve ark., 1994; Cavalli ve ark., 2000; Chim ve ark., 2001; Palacios ve ark., 2007; Immanuel ve ark., 2007; Sui ve ark., 2007). Bütün bunlar, n-3 HUFA'ca zengin Artemia ile beslenen canlıların çevresel koşullarla başa çıkma kabiliyetini doğrulamaktadır. Mevcut bulgulara benzer şekilde, Tackaert ve ark. (1989) ve Immanuel ve ark. (2007), n-3 HUFA ile zenginleştirilmiş Artemia'nın, P. monodon postlarvalarında daha yüksek hayatta kalma süresine sahip olduklarını saptamışlardır. Chim ve ark. (2001), daha yüksek n-3 HUFA seviyelerinin beslenmesinin, Litopenaeus stylirostris'in hücresel membran direncini arttırdığını ve bununda çevresel değişikliklere toleransı arttırdığını göstermiştir. Bu nedenle, n-3 HUFA eksik yemlerle beslenen penaeidlerin genellikle strese karşı düşük bir tolerans gösterdikleri kabul edilmektedir (Chim ve ark., 2001; Palacios ve Racotta, 2007). Mutti ve ark (2017) n-3 yă asitlerince zenginleştirilmiş Artemia ile besledikleri karides (Farfantepenaeus paulensis) larvalarını (PL8) deneme sonunda tuzluluk ve amonyak stress testlerine tabi tutulduklarında zenginleştirilmiş Artemia ile beslenen grubun stres direncinin ve büyümeyi etkilendiğini belirlemişlerdir.

Tablo 2. Zenginleştirilmemiş artemia ve HUFA'ca zenginleştirilmiş artemia ile 12 gün boyunca beslenen Yeşil kaplan karidesi (Penaeus semisulcatus) larvalarının büyüme parametreleri

\begin{tabular}{|c|c|c|c|c|c|c|c|c|}
\hline \multirow[t]{2}{*}{ Grup } & \multicolumn{3}{|c|}{ Yaşama Oranı (\%) } & \multicolumn{2}{|c|}{ Büyüme Oranı (mm/day) } & \multicolumn{3}{|c|}{ Total Boy (mm) } \\
\hline & M1 & PL1 & PL9 & M1- PL1 & M1- PL9 & M1 & PL1 & PL9 \\
\hline WE & 100 & $80.80 \pm 1.3^{\mathrm{c}}$ & $73.05 \pm 1.5^{\mathrm{b}}$ & $0.62 \pm 0.4^{\mathrm{b}}$ & $0.48 \pm 0.1^{\mathrm{b}}$ & $3.02 \pm 0.3$ & $5.34 \pm 0.5$ & $8.97 \pm 0.3^{b}$ \\
\hline SELC & 100 & $93.20 \pm 1.4^{\mathrm{a}}$ & $79.13 \pm 0.9^{a}$ & $0.67 \pm 0.3^{\mathrm{a}}$ & $0.58 \pm 0.1^{\mathrm{a}}$ & $3.02 \pm 0.3$ & $5.36 \pm 0.0$ & $9.25 \pm 0.2^{\mathrm{a}}$ \\
\hline
\end{tabular}

Sonuçlar ortalama \pm standart sapma $(\mathrm{n}=3)$ şeklinde verilmiştir. Gruplar arasındaki istatistiksel fark $\mathrm{P}<0.05$ önem düzeyinde karşılaştırılmıştır. Satırlardaki farklı harfler istatistiksel farklılıkları göstermektedir $(\mathrm{P}<0.05)$.

\section{Sonuç}

$\mathrm{Bu}$ çalışmada, P. semisulcatus larva yetiştiriciliğinde $\mathrm{n}-3$ HUFA ile zenginleştirilmiş Artemia ile beslemenin yaşama ve büyüme oranını etkilediği bulunmuştur. Ayrıca, n-3 HUFA'nın deniz larva kültüründe kullanılan diğer canlı yemlerin e-ISSN: 2148-2683 zenginleştirilmesi için kullanıldığında da etkili olabilir. Böylece kuluçkahanelerde uygulama potansiyeli yüksektir. Ayrıca n-3 HUFA ile zenginleştirilmiş Artemia'lar ile larva besleme sonrasında karideslerde fizyolojik etkileri açıklamak için genomik çalışmalara ihtiyaç vardır. 


\section{Kaynakça}

Agh, N., \& Sorgeloos, P. (2005). Handbook of protocols and guidelines for culture and enrichment of live food for use in larviculture. Urmia-Iran: Ediciones Artemia \& Aquatic Animals Research Center, 60.

Bell, M. V., Henderson, R. J., \& Sargent, J. R. (1986). The role of polyunsaturated fatty acids in fish. Comparative Biochemistry and Physiology Part B: Comparative Biochemistry, 83(4), 711-719.

Cavalli, R. O., Berghe, E. V., Lavens, P., Thuy, N. T., Wille, M., \& Sorgeloos, P. (2000). Ammonia toxicity as a criterion for the evaluation of larval quality in the prawn Macrobrachium rosenbergii. Comparative Biochemistry and Physiology Part C: Pharmacology, Toxicology and Endocrinology, 125(3), 333-343.

Chim, L., Lemaire, P., Delaporte, M., Le Moullac, G., Galois, R., \& Martin, J. L. M. (2001). Could a diet enriched with n-3 highly unsaturated fatty acids be considered a promising way to enhance the immune defences and the resistance of Penaeid prawns to environmental stress?. Aquaculture research, 32(2), 91-94.

Cobo, M. D. L., Wouters, R., Wille, M., Sonnenholzner, S., \& Sorgeloos, P. (2015). Evaluation of frozen Umbrella-stage Artemia as first animal live food for Litopenaeus vannamei (Boone) larvae. Aquaculture Research, 46(9), 2166-2173.

Dhert, P., P. Lavens \& P. Sorgeloos. (1992). Stress evaluation: a tool for quality control of hatchery- produced shrimp and fish fry. Aquacult. Europe, 17: 6- 10.

FAO (2016) Food and Agriculture Organization of the United Nations. Rome

Figueiredo, J., R. Van Woesik \& J. Lin. (2009). Artemia franciscana enrichment model- How to keep them small, rich and alive. Aquaculture, 294: 212-220.

Immanuel, G., T. Citarasu, V. Sivaram, M.M. Babu \& A. Palavesam. (2007). Delivery of HUFA, probionts and biomedicine through bioencapsulated Artemia as a means to enhance the growth and survival and reduce the pathogenesity in shrimp Penaeus monodon postlarvae. Aquacult. Int., 15: 137-152.

Jinbo, T., Dan, S., Nakaya, M., Ashidate, M., \& Hamasaki, K. (2013). Effects of n-3 highly unsaturated fatty acid content in Artemia on survival and development of laboratory-reared horsehair crab Erimacrus isenbeckii larvae. Fisheries science, 79(3), 459-467.

Jones, D. A., Kamarudin, M. S., \& Vay, L. L. (1993). The potential for replacement of live feeds in larval culture. Journal of the world Aquaculture Society, 24(2), 199-210.

Kanazawa A, Teshima SI, Sakamoto M (1985) Effects of dietary lipids, fatty acids, and phospholipids on growth and survival of prawn (Penaeus japonicus) larvae. Aquaculture 50(12):39-49. https://doi.org/10.1016/0044-8486(85)90151-6

Kanazawa, A., Teshima, S., Ono, K., (1979a). Relationship between essential fatty acid requirements of aquatic animals and capacity of bioconversion of linolenic acid to highly unsaturated fatty acid. Comp. Biochem. Physiol. B, 63:295298.
Kanazawa, A., Teshima, S., Ono. K., Chalayodeja, K., (1979b). Biosynthesis of fatty acids from acetate in the prawn, Penaeus monodon and Penaeus merguiensis. Mem. Fac. Fish. Kagoshima Univ., 28: 21-26.

Kumlu, M. (1999). Feeding and digestion in larval decapod crustaceans. Turkish Journal of Biology, 23(2), 215-230.

Lavens, P. \& P. Sorgeloos. (1996). Manual on the produc- tion and use of live food for aquaculture. FAO, Rome, $295 \mathrm{pp}$.

Lèger, P. \& P. Sorgeloos. (1992). Optimized feeding regimes in shrimp hatcheries. In: A.W. Fast \& J.L. Lester (eds.). Marine shrimp culture: principles and practices. Elsevier, Amsterdam, pp. 225-244.

Lèger Ph, Bengston DA, Simpson KL, Sorgeloos P (1986) The use and nutritional value of Artemia as a food source. Oceanogr Mar Biol Annu Rev 24:521-623

Martins, T.G., R.O. Cavalli, R.C. Martino, C.E.M. Rezende \& W. Wasielesky Jr. (2006). Larviculture output and stress tolerance of Farfantepenaeus paulensis postlarvae fed Artemia containing different fatty acids. Aquaculture, 252: 525-533.

Metcalfe, A.P. \& A.A. Schmitz. 1961. The rapid preparation of fatty acids for gas chromatographic analysis. Anal. Chem., 33: 363-364.

Mutti, D.W., Ballester, E.L.C., Wasielesky Jr., R.C.M.W., Cavalli, R.O., (2017). Feeding n-3 HUFA enriched Artemia to the larvae of the pink shrimp Farfantepenaeus paulensis increases stress tolerance and subsequent growth. Lat. Am. J. Aquat. Res., 45(1): 18-24

Palacios, E. \& I.S. Racotta. (2007). Salinity stress test and its relation to future performance and different physiological responses in shrimp postlarvae. Aquaculture, 268: 123-135.

Rees, J.F., Cure, K., Piyatirattivorakul, S., Sorgeloos, P., Menasveta, P., 1994. Highly unsaturated fatty acid requirements of Penaeus monodon postlarvae: an experimental approach based on Artemia enrichment. Aquaculture, 122: 193-207.

Sorgeloos, P., Coutteau, P., Dhert, P., Merchie, G., \& Lavens, P. (1998). Use of brine shrimp, Artemia spp., in larval crustacean nutrition: a review. Reviews in fisheries science, 6(1-2), 55-68.

Sui, L., Wille, M., Cheng, Y., \& Sorgeloos, P. (2007). The effect of dietary n-3 HUFA levels and DHA/EPA ratios on growth, survival and osmotic stress tolerance of Chinese mitten crab Eriocheir sinensis larvae. Aquaculture, 273(1), 139-150.

Tackaert, W., Abelin, P., Leger, P. H., \& Sorgeloos, P. (1989). Stress resistance as a criterium to evaluate quality of postlarval shrimp reared under different feeding procedures: 393-403. In III Simposio Brasileiro Sobre Cultivo de Camarao (pp. 393-403). MCR Aquacultura.Van Stappen 1996

Wouters, R., Cobo Barcia, M. D. L., Dhont, J., \& Wille, M. (2009). Developments in feed formulations, feeding practices and culture techniques for marine shrimp larvae. In WAS Special session on Sustainable Shrimp (pp. 79-91). World Aquaculture Society (WAS). 